\section{Dos Ecossistemas aos Descaminhos da Geografia}

\author{
Mario B. Aragão *
}

Este belíssimo livro irmana ciência, arte e divulgação científica. Trata-se de um desses livros que as grandes empresas publicam para oferecer como brinde de Natal. No caso, é uma empreiteira de grandes obras de engenharia. $O$ seu presidente aproveita a apresentação do livro para justificar a sua atividade. Ao falar dos relatórios de impacto ambiental (RIMA) esquece, entretanto, de dizer que a maioria deles são "frios" e que o destino de todos é repousar na gaveta de algum tecnocrata.

Procura justificar a realização, pelos últimos governos, de grandes obras de engenharia, com o papel que elas teriam em livrar da miséria uma grande parcela da população brasileira, o que os fatos não comprovam. Além disso, se as obras são necessárias ou não, cabe à sociedade e não aos empreiteiros decidir.

O texto dos autores começa com uma crítica ao IBDF, por não dispor de dados sobre a ação antrópica nos diversos ecossistemas, mas podia ter outras. Diversas fotografias são de Estaçōes Ecológicas, que são unidades de conservação da natureza muito mais eficientes do que as do IBDF. Nunca é demais ressaltar essa iniciativa do Prof. Paulo Nogueira Neto, quando esteve à testa da Secretaria Especial do Meio Ambiente (SEMA). Essas Estações representam uma mudança de mentalidade, conservar e estudar e não apenas conservar os parques até que um incêndio os destrua, como tem ocorrido.

O texto da parte florestal, apesar de revisto por Antônio Houaiss, conserva a personalidade de Rizzini. As fotografias são ótimas e muito bem combinadas. Por exemplo, ocupando um par de páginas aparece, de um lado, dois quatis trepados em duas árvores $\mathrm{e}$ do outro, um mata-pau envolvendo o tronco de uma árvore. Parece até que os autores quiseram mostrar que subir em árvore não é privilégio de animal. Em outro par, de um lado um sagüi trepado num galho e do outro, uma grossa liana pendurada numa árvore. Uma preguiça abraçada num tronco e, abaixo, as flores de abricó-de-macaco, que brotam do caule.

$\mathrm{Na}$ descrição da mata atlântica destaca-se um aspecto que não foi mencionado na Amazônia, o colorido observado nas diversas épocas do ano, devido à floração das árvores. É que em áreas montanhosas, se observa a floresta vista de cima.

Cadernos de Saúde Pública, RJ, 5(3): 345-356, jul/set. 1989
Ecossistemas brasileiros. Carlos Toledo Rizzini, Adelmar Coimbra Filho e Antônio Houaiss. ENGE-RIO/Editora Index, Rio de Janeiro, $1988,200 \mathrm{p}$.
* Pesquisador Titular da Escola Nacional de Saúde Pública. 
A síntese dos estudos de Roberto Klein, sobre a evolução dos pinhais para floresta atlântica é de leitura muito agradável. A té pouco tempo não se sabia que os pinheirais do sul do Brasil, são uma vegetação de transiçāo.

Muito boa a explicação do que vem a ser cerrado, o que não é de estran har, pois, Rizzini tem trabalhado muito com esse tipo de vegetação. É também essa sua intimidade com o cerrado que permitiu explicar, de maneira singela, o funcionamento desse tipo de vegetação. Depois de lembrar que as queimadas são um fenômeno universal, mostra que, bem conduzido, o fogo é benéfico à vegetação do cerrado porém, quando exagerado, é calamitoso.

De maneira clara, define o cocal ou babaçual, como uma vegetação degradada pela ação do homem e estimulada pelo fogo.

Considerar a caatinga um mosaico de vegetação é perfeito. Loefgren já chamara a atenção para os dois grupos de espécies, umas permanentes e outras periódicas.

A vegetação do Pantanal designada, nas publicações do IBGE, de "complexo do Pantanal" é, na realidade, complexa. Nele se encontram espécies de vários biomas brasileiros, caatinga, cerrado, mata atlântica e floresta amazônica. O mesmo ocorrendo com a fauna.

Deixamos para o fim o comentário sobre o capítulo que abre o livro, a mata amazônica, porque nele sente-se a falta de familiaridade do autor com a regiăo. Tudo está correto, ainda mais que está citado o primoroso artigo de Murça Pires e Ghillean Prance, do Amazonia (Key environments), analisado nestes Cadernos (Cad. Saúde Públ.,RJ., 4 (1), 1988), mas nota-se pouco desembaraço.

Para nós que estamos na FIOCRUZ, o livro traz ainda uma grata surpresa. O mapa fitogeográfico que ilustra a obra é do Atlas Florestal do Brasil, elaborado em Man guinhos por Henrique Veloso e atualizado pelo próprio, hoje dando colaboraçāo ao IBGE. Isso é mais um exemplo da força do antigo Instituto Oswaldo Cruz, uma vez que Veloso, juntamente com Oliveira Castro, foram os fundadores da ecologia no Instituto.

Glossário de ecologia. Shigueo Watanabe (Coordenador geral). Publicaçāo ACIESP n: 57, Academia de Ciências do Estado de São Paulo, São Paulo, 1987, $271 \mathrm{p}$.
Este sim é um senhor glossário; além disso cobre um campo bem mais vasto do que o da ecologia. Logo na primeira página encontram-se termos de geomorfologia, oceanografia, meteorologia e, naturalmente, ecologia. E útil também para os que se dedicam à parasitologia, que é um ramo da ecologia e à engenharia sanitária, que não deixa de ser uma ecologia aplicada. 
Nos verbetes relativos à entomologia sanitária nota-se que diversos termos costumam ser usados de forma incorreta. Infelizmente, também temos incorrido nessa infração.

No verbete "controle biológico aplicado" fala que "o nível econômico de dano ou parâmetro equivalente (...) seria aplicado para casos de vetores de doenças."

O controle biológico tem sido pouco aplicado em saúde pública e não conhecemos nenhum caso em que algum nível ie dano seja conhecido. Entretanto, existe um parâmetro clássico sobre a transmissão da febre amarela, que é o índice predial, de Aedes aegypti, inferior a $5 \%$, quando deixa de ocorrer transmissão da doença. Todavia, nesse caso, o índice tem sido conseguido, geralmente, com um controle integrado, onde a contribuição de agentes biológicos tem sido pequena. Não resta dúvida que se trata de um campo de pesquisas quase virgem e que está a merecer trabalho sério.

Muito interessante o conceito de tipo, no verbete "espécie tipológica". Os tipos reuniriam "as características supostamente comuns e restritas a todos os indivíduos da espécie." Não resta dúvida que o tipo aind a é imprescindíve!, mas, esse "supostamente" está muito bem colocado.

O glossário divide a "estimativa do impacto ambiental" que, na prática, seria consubstanciada no relatório de impacto ambiental (o famoso RIMA), em duas fases. Uma preditiva e outra de monitoramento, durante a construção e após o término do empreendimento. Coisa que nunca vimos ser feita.

Ao definir Mata Atlântica diz que ela "distribui-se de Natal (RN) até o Município de Torres (RS)". $\hat{E}$ muito otimismo, o correto seria dizer que ela se distribuía, pois restam poucos núcleos.

No verbete mata de cipó, esqueceram de mencionar a sua presença na Amazônia onde, atualmente, situa-se a sua maior área.

Muito interessante e econômico, o sistema de, em seguida aos verbetes dos prefixos e dos sufixos, colocar todas as combinaçōes usadas em ecologia.

Depois do final do glossário foram colocados 46 apêndices. Alguns muito úteis mas outros, como os 9 referentes ao solo, são detalhados demais. Alguns, como os de unidades de medida e de elementos químicos, ficariam melhor em manuais técnicos.

Os dois apêndices finais, as leis que criaram as estações ecológicas e a política do meio ambiente, apresentam uma curiosidade. Foram referendadas pelo Ministro Mario Andreazza, o homem da Transamazônica, da Perimetral Norte e outras estradas, que deslancharam a destruição da floresta amazônica.

Depois da bibliografia geral, colocaram uma bibliografia de termos regionais completíssima, com a citação de diversas obras raras.

Cademos de Saúde Pública, RJ, 5(3): 345-356, jul/set. 1989 
Uma obra como essa, apesar de ter contado com 24 colaboradores não pode ser feita da noite para 0 dia e informaçōes contidas no prefácio, permitem concluir que ela representa mais de 10 anos de trabalho. Quem já tomou parte em obra coletiva pode avaliar o esforço que devem ter despendido o coordenador geral, por sinal um físico, e seus colaboradores.

Em suma, uma obra de imensa utilidade e que honra a Academia de Ciências do Estado de São Paulo.

A sinecura acadêmica: a ética universitária em questāo. Edmundo Campos Coelho. Vértice, Editora Revista dos Tribunais, São Paulo, $1988,143 \mathrm{p}$.
Como é comum entre as pessoas formadas em sociologia, o autor fala muito e diz pouco. Isso é uma pena, porque o pouco que diz é excelente, mas, tem que ser garimpado em longas leituras.

$O$ conjunto de cursos que aqui denominam de universidade teve um mal começo, uma vida melancólica e está tendo um triste fim. Isso á preocupante, pois, parece se ajustar muito bem ao pensamento da nossa sociedade. Todas as tentativas de criar universidades sérias ou foram cortadas violentamente ou adaptadas ao modelo geral.

Perfeita a descriçāo da mentalidade dos componentes da chamada comunidade científica. O seu elitismo chega a ser doentio, igual aos membros da comunidade de informação; eles também se consideram uma coletividade acima de qualquer suspeita. Só podem ser avaliados por seus pares.

Está muito bem documentado o fato dos governos militares terem aumentado muito os recursos para a pesquisa científica. O que, naturalmente, continuou na nova república. Em alguns lugares essa inundação de dinheiro foi desastrosa. Conhecemos um em que desandaram a construir prédios, comprar equipamentos sofisticados e contratar gente por atacado, sem resultados proporcionais.

Muito lúcida a análise da confusão que as agências financiadoras da pesquisa estão criando nas universidades e nos institutos. Transformaram o pesquisador num èmpresário que, como tal, tem que usar as artimanhas próprias desses profissionais. Outra anomalia fomentada por essas agências é a explosão da pós-graduação, que passou a se justificar a si mesma. Um diretor de unidade da UFRJ fez uma palestra aqui na Escola, em que a pós-graduaçāo era apresentada como uma linha de montagem de uma fábrica. Cada doutor, durante um período de cinco anos, tinha que formar tiês novos doutores e, desse modo, a cada cinco anos o número de doutores seria quadruplicado. Isso, naturalmente, até o infinito. Na mesa, dessa conferência, estavam representantes de três agências financiadoras, isto é, agências que fazem a mesma coisa. 
É o caso de se dizer: como jogam dinheiro fora! Sob esse aspecto, 0 autor esquece de dizer que, em muitos lugares, a pós-graduação funciona como puro seguro desemprego. Enquanto não aparece coisa melhor, o jeito é sobreviver com a bolsa.

Há quem diga que se, num dia, o governo proibisse a pós-graduação, no dia seguinte o ensino melhoraria substancialmente. Sob esse aspecto, o livro transcreve uma opiniảo do Prof. Carlos Chagas Filho, que nos parece fundamental: "Acho mesmo conveniente variar o ensino do pesquisador de acordo com a sua categorização. Quanto melhor e mais amadurecido, mais se utilizará o professor no ensino inicial. Aí ele dará as grandes linhas, mostrará o que é realmente relevante, e não se perderá em detalhes." Foi justamente o contrário disso que o programa de pós-graduação fez. Colocou nela os "cardeais" e deixou os alunos de graduação entregues ao "baixo clero".

Discordamos de algumas opiniōes do autor mas, no geral, o livro é um grito de alerta para o caos em que estão mergulhando o nosso ensino e a nossa pesquisa científica.

Duas coisas causam surpresa ao leitor desse dicionário. Uma, é que a classificação toxicológica dos praguicidas está num capítulo que antecede o que define os parâmetros utilizados. A outra, é que as ilustraçōes são todas de máquinas que não têm nada a ver com o controle fitossanitário. No final, descobre-se que o motivo foi o patrocínio. Uma coisa muito em moda, mas que não é nada boa.

Os autores aceitam, sem restriçōes, a classificaçāo toxicológica feita pelo Ministério da Saúde, numa época em que ele nâo tinha pessoal familiarizado com o assunto. Aliás ela já poderia ter sido revista pois, atualmente, a Fiocruz possui gente capacitada para isso.

A crítica à Portaria que oficializou o receituário agronômico é leve. Não deram ênfase ao grande "furo" que é deixar livre a venda de produtos pouco tóxicos, pois, com uma formulação mais diluída, faz-se um ingrediente ativo passar de uma classe para outra.

A parte de precauções para uso adequado está muito bem feita, mas, com pouco destaque. Numa nova edição, os autores devem colocá-la num capítulo a parte.

As instruções para primeiros socorros estão ótimas. Muito melhores do que as do manual de praguicidas do Ministério da Saúde. Os autores deste manual já haviam sugerido que essa parte fosse tirada em separado e distribuída a todos os postos de saúde do

Cademos de Saúde Pública, RJ, 5(3): 345-356, jul/set. 1989
Dicionário de pragas e praguicidas. Aurino Florencio de Lima e Francisco Racca Fitho. Rio de Janeiro, Edição dos autores, 1987, $122 \mathrm{p}$. 
Receituário agronômico. Milton de Souza Guerra e Daiser Paulo de A. Sampaio. Editora Globo, Rio de Janeiro, $1988,436 \mathrm{p}$. país. Renovamos essa sugestão mas, já agora, com o texto que está nesse dicionário.

Existe uma crença generalizada de que os inseticidas fosforados e os carbamatos têm uma persistência curta no meio-ambiente. A tabela 5, do dicionário, mostra que isso não é, totalmente, verdadeiro. $O$ que se considera persistência curta é uma meia vida de até 90 dias e alguns fosforados têm persistência média, que varia entre 90 e 180 dias.

Muito útil a relação das diversas culturas com os defensivos autorizados e outras informaçōes, como o periodo de carência, isto é, o número de dias nue deve decorrer entre a última aplicação e a colheita. Entretanto, esse é um assunto em que não existe muita seriedade. Para os produtos de exportação esse período é sempre mais longo do que para os de consumo interno e ainda mais curto para os de alimentação animal. Assim, o período de carência do malation para o café é de 15 dias, para o feijão de 3 dias e para as forragens de 0 a 5 dias. Felizmente, isso não acontece apenas no Brasil. Trabalhamos com um inseticida sistêmico (que é absorvido pela planta e circula na seiva) que, na Europa, tem período de carência, para alimentos do homem, de 20 a 28 dias e, para forragens, de 7 dias.

Encerra esse conciso dicionário uma relaçāo dos níveis populacionais, que exigem medidas de controle, das pragas das principais lavouras do país.

Os autores são professores da Universidade Federal Rural do Rio de Janeiro o que, por si só, garan te a qualidade do trabalho.

O livro começa com um histórico conciso e muito bom, do combate a pragas e doenças da lavoura. Curioso que as etapas do controle fitcssanitário casam bem com a evolução da biologia. Primeiro visava-se a espécie e hoje a preocupação é com a população da praga.

Entendemos muito bem a queixa contra a falta de pesquisas, feitas pelo governo, sobre produtos fitossanitários. Tomamos parte na elaboração do manual de praguicidas do Ministério da Saúde e sentimos o problema. O grosso das informaçōes disponíveis vem das publicaçōes da OMS $€$ da FAO, que colhem a maior parte delas nas indústrias. Dessa forma, a quase totalidade desse manual é unia compilação, pois, apenas três de seus autores tinham, episodicamente, feito alguma pesquisa com produtos nele mencionados.

Talvez devido à insegurança que ainda domina o problema da implantação do receituário agronômico, 
as instruções dadas para a feitura das receitas são excessivamente minuciosas e impossíveis de serem levadas em conta.

As recomendações para a escolha das formulaçōes e da técnica de aplicação são muito úteis para o pessoal de saúde pública.

A parte de nível econômico de dano e controle integrado de pragas tem muita conversa fiada e nota-se que os autores não dominam o assunto. Entretanto, esses dois assuntos são de muita importância para a saúde pública. Sabe-se que o fracasso da atual campanha contra os Aedes aegypti e albopictus decorre de diversos fatores mas, uma diferença entre ela e as anteriores, é que ela usa apenas inseticidas, enquanto as anteriores, que tiveram êxito, usavam controle integrado. A questão do nível de dano precisa merecer uma consideração em relação à malária. As informações que se têm, de Cuba e do Estado de São Paulo, mostram que fica cara a manutenção da erradicação. Além do mais, um trabalho que está sendo publicado nos "Cadernos", aqui na Escola, mostra que os postos de saúde do estado e do município, não são eficientes na vigilância contra a introdução de casos de malária.

Uma parte substancial do livro informa sobre os produtos registrados, pelos Ministérios da Agricultura e da Saúde, para as diversas pragas e o seu modo de aplicação. Assunto que não tem sido muito respeitado pelo Ministério da Saúde.

Muito útil a parte de tratamento de intoxicações, tanto em pessoas como em animais domésticos. Estes últimos, geralmente, não são levados em conta nos manuais correntes, o que é lastimável porque seu tratamento é mais complicado.

Em suma, um livro muito útil para todos que lidam con esses "fantasmas" que os "ecologistas" chamam de agrotóxicos ou biocidas.

Conhecemos rapidamente o Prof. Manuel Correia de Ancirade quando trabalhávamos no Projeto RADAMBRASIL, mas logo percebemos tratar-se de um homem que tem os pés no chão. Neste livro ele reúne uma série de artigos publicados entre 1984 e 1987 , portanto já fora do período de repressão político-militar mais intensa.

No começo assusta um pouco ele utilizar muito a palavra reflexāo, que é usada e abusada, geralmente, sem muito sentido aqui nesta Escola. Passado o susto, entra-se num livro riquíssimo em idéias e análises.

Logo na primeira página é duro com os adeptos da geografia clássica, que defendem uma hipotética Cadernos de Saúde Pública, RJ, 5(3): 345-356, jul/set. 1989
Caminhos e descaminhos da geo grafic. Mnoel Correia de Andra de. Campinas, SP, Papirus editora, $1989,85 \mathrm{p}$. 
neutralidade do conhecimento científico. Mostra logo como o uso indiscriminado dos métodos matemáticoestatísticos conduziu os geógrafos a uma posição útil ao planejamento sem preocupações ecológicas e sociais. O que, por sua vez, levou à mais completa alienação da realidade nacional. É o que fazem os nossos colegas da ciência pura, a pesquisa desinteressada, como dizia o Prof. Olímpio da Fonseca, que quando, por acaso, produz alguma coisa útil, vai ser aproveitada pelos países desenvolvidos.

Grande parte do livro é utilizada para mostrar como, historicamente, os geógrafos sempre trabalharam a serviço da expansão colonial e, também, na consolidação do domínio sobre os povos colonizados. Curiosamente, eles foram mais sinceros do que os que praticaram a saúde pública. A princípio chamavam essa geografia dos dominadores da geografia colonial e somente mais tarde passaram a denominá-la de geografia tropical. Na saúde pública a posição é inversa. A chamada medicina tropical, apesar de feita por médicos militares, nunca se assumiu como medicina colonial. Denominação que só vimos mencionada por espíritos progressistas, como o Prof. Samuel Pessoa.

Interessantíssima a evolução da geografia brasileira na alternância, sofrida pelo país, de períodos autoritários e democráticos, que o au tor prefere chamar de populistas. O pessoal da quantificação e do computador che gou ao auge na ditadura militar. Lógico que o computador é uma forma de compensar a falta de espírito crítico, mas não é só isso.

Desde que estagiamos num laboratório da Marinha dos Estados Unidos, ficamos convencidos de que riqueza de equipamento é característica de país subdesenvolvido. Nessa época já havíamos trabalhado na América Central, onde havia mais aparelhagem sofisticada do que aqui no Brasil.

Discutindo a crise da geografia, o autor lembra que, inicialmente, o geógrafo tem que ter uma boa formaçāo científica. Numa época em que tivemos contato com geógrafos brasileiros e estrangeiros, notamos uma grande diferença na formação básica. Por mais que os brasileiros se es forçassem, suas análises ficavam sempre muito na superfície. Isso se observa também na produção atual da Fiocruz. Os graduados das faculdades particulares que passaram a freqüentar Manguinhos depois da cassaçāo de 1970 , não estão dando conta do recado.

Esse é um problema sério e se não for enfrentado com decisão, a FIOCRUZ do futuro será muito triste.

O Prof. Samuel Pessoa sempre foi um entusiasta da geografia médica e nós também pensamos que a geografia é fundamental para a compreensão dos problemas de saúde pública. 